\title{
ACERCA DE LAS BASES PSICOANALITICAS DEL ESTUDIO DE LA PARENTALIDAD
}

\author{
Nombre: Leticia Solis Ponton ${ }^{1}$ \\ Afiliación: Universidad de Paris VII y UNAM \\ Dirección elctrónica: leticiasolisp@yahoo.fr
}

\section{Resumen}

Las nociones que a continuación, por razones de espacio, son expuestas de manera esquemática, son el fruto de los trabajos realizados durante 27 años de colaboración con el Profesor Serge Lebovici, psicoanalista francés quien dedicó sus esfuerzos en la Universidad de Paris XIII Bobigny, a la prevención y al tratamiento precoz del sufrimiento psíquico del niño y de la familia. Es pues una aplicación del psicoanálisis al campo del estudio del vínculo padres-hijo, toma en consideración así mismo los aportes de la investigación psiconeurológica de las capacidades del feto y del recién nacido (R. Emde 1990), los aportes de la psicoterapia familiar (R. Kaes 1993), en fin los trabajos de Sigmund Freud dirigidos al campo de la cultura y la transmisión a través de las generaciones (1914) y continuados en el campo del etnopsicoanálisis por Georges Devereux (1985); en esta perspectiva se asume que psiquismo y cultura son co-emergentes, la parentalidad se sitúa en el núcleo de lo humano.

La Parentalidad supone un proceso psíquico que se diferencia de la reproducción biológica y del parentesco como ha sido estudiado por los antropólogos.

El psicoanálisis introduce la complejidad del aparato psíquico en la construcción de la Parentalidad. Sabemos que el aparato psíquico no esta hecho de una pieza, funcionamos con diferentes estados: consciente, preconsciente e inconsciente. Pero también la dimensión estructural del aparato psíquico nos confronta a diferentes entidades que integran el aparato psíquico:

- EI YO: instancia que se encarga de los intercambios con el medio ambiente, funciona sobre el principio de la realidad y también es el mediador entre las diferentes tendencias o fuerzas internas.

1 Doctora en Psicología, Universidad de Paris VII y UNAM. Miembro de la Société Psychanalytique de Paris (SPP) y de la Asociación psicoanalítica Mexicana (APM). Directora de los diplomados Internacionales de Parentalidad y de Psicoterapias bebé-padre.

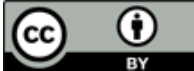




\section{GRAFO Working Papers}

Número 3, enero 2014. No 03/01. ISSN: 2014-5993

- EI ELLO: que alberga las pulsiones sexuales y agresivas que luchan por expresarse sin tomar en cuenta las condiciones de la realidad, el ELLO funciona bajo el principio del placer.

- EI SUPERYO: instancia que representa los valores morales, los principios, tradiciones y los ideales. Es heredera de las restricciones parentles, tal como el niño las vivió o las interpretó en la infancia. EI SUPERYO puede ser rígido, punitivo y tiranizar al yo imponiendo sus exigencias difíciles de cumplir y en ocasiones fuera de la realidad.

La lucha entre las instancias psíquicas constituye la base de lo que conocemos como conflicto psíquico o neurosis.

EI YO PARENTAL: instancia capaz de elaborar el conflicto psíquico para convertirse en padre o madre.

Este conflicto psíquico nos explica fenómenos como ambivalencia acentuada, rechazo a la maternidad o secuelas de una infancia difícil que pueden constituir situaciones de riesgo para la Parentalidad.

La construcción de la Parentalidad en el aparato psíquico se inicia con el deseo del hijo, que durante el embarazo moviliza las representaciones que la futura madre va a crear en su mente pensando en su bebé, estas aunadas al deseo de bebé, van a preparar el espacio psíquico que acogerá al bebé real al nacer. Podemos distinguir por lo menos cuatro tipos de representaciones del bebé antes de nacer:

- BEBE IMAGINARIO: el bebé que la madre imagina antes del nacimiento

- BEBE DE LA FANTASÍA INCONSCIENTE DE LA MADRE, asociada generalmente a conflictos inconscientes no elaborados.

- BEBE NARCISISTA: el bebé del narcisismo de la madre

- BEBE CULTURAL: el bebé de la cultura de la madre

El BEBE REAL: Este es el hijo en su corporeidad que al nacer será confrontado a las representaciones mentales que la madre ha construido. Pero el bebé por su parte, posee desde el nacimiento facultades y potencialidades que van intervenir en la parentalisation que éste realizara de su madre y de su padre.

Así se cristaliza la Parentalidad cuando la madre y el padre se reconocen como padres de SU hijo. 


\section{GRAFO Working Papers}

Número 3, enero 2014. No 03/01. ISSN: 2014-5993

UN PROCESO CON DOS POLOS: La Parentalidad constituye un proceso psíquico con dos polos, en uno el convertirse en padres o Parentalidad propiamente dicha, en el otro, la filiación, el reconocerse como hijo de sus padres y aceptar lo que hemos aceptado de ellos.

La filiación se correlaciona con la afiliación, como proceso de adherir a la cultura y a sus instituciones representativas. Cuando la filiación se ve perturbada, encontramos con frecuencia problemas en la afiliación, por ejemplo en el caso de ruptura familiar o de familias en migración.

TRANSMISIÓN: El anuncio de la venida de un bebé moviliza al menos tres generaciones y el entorno cultural en que éste nacerá.

La cuestión de la transmisión es esencial en la Parentalidad, la madre y el padre al imaginar el bebé piensan lo que le van a transmitir: tradiciones, valores, afectos y una historia que constituye la herencia psíquica de cada ser humano, su árbol de vida.

Existen dos tipos de transmisión:

- Transmisión intergeneracional: de padres a hijos

- Transmisión transgeneracional: a través tres o más generaciones

MANDATO TRANGENERACIONAL. La herencia psíquica también incluye los conflictos inconscientes de la madre, del padre y de los abuelos. Esta puede traducirse como un mandato transgeneracional y constituir un obstáculo para el desarrollo del niño en la cultura donde se desarrolla.

UN ORDEN SIMBOLICO. La Parentalidad implica también la aceptación de un orden primario, un orden simbólico en los intercambios familiares y en el aparato psíquico, este implica la triple diferencia:

- Diferencia de Yo-No-Yo

- Diferencia de género

- Diferencia de generaciones

Este orden simbólico es coemergente y condición de la cultura, como lo muestra S. Freud en su obra Tótem y Tabú (1914). 
Número 3, enero 2014. No 03/01. ISSN: 2014-5993

TRANSPARENCIA PSIQUICA Y PERINATALIDAD. La complejidad de la organización de la Parentalidad justifica que los futuros padres necesiten ser acompañados y apoyados por su entorno cultural que va a actuar como una red protectora de la fragilidad psíquica y física que acompaña el embarazo y la perinatalidad

En efecto, durante el embarazo y el postparto, ocurren movimientos progredientes en que la futura madre se identifica con su propia madre para cuidar de su hijo. Estos cohabitan con movimientos regredientes o regresivos, en que la futura madre se identifica con el bebé que lleva en sus entrañas y necesita ser cuidada y atendida como ella lo fue durante su infancia o como hubiese querido serlo.

Este estado se conoce como "transparencia psíquica de la peri natalidad" porque durante el mismo re-emergen elementos propios de su historia edipica y pre-edipica que normalmente han sido olvidados o reprimidos.

LAS CONSTELACIONES FAMILIARES DE NUESTROS DÍAS. Muestran cambios muy importantes, emergen nuevas constelaciones familiares y las condiciones culturales $\mathrm{y} / \mathrm{o}$ sociales muchas veces dificultan el contacto con la familia extensa. La madre puede encontrarse en una situación de aislamiento, propicia para perturbaciones como la depresión materna pre y postpartum.

Esto revela la importancia del acompañamiento profesional de las familias en el embarazo y la peri-natalidad.

La experiencia clínica nos muestra el alto valor preventivo de las intervenciones tempranas de acompañamiento y/o de ayuda de la triada madre-padre-hijo. La prevención debe entenderse en relación a la madre y a la familia, pero también y sobre todo, en relación a la construcción psíquica del niño.

LA TRIADA PRIMARIA Y EL DESARROLLO DEL HUMANO. El desarrollo psíquico del niño se realiza sobre las bases de los cuidados maternos: La madre a través de los cuidados que prodiga a su bebé, también transmite su propia vida psíquica.

El padre interviene igualmente desde el principio en el desarrollo del ser humano: de manera indirecta, a través de la madre y también de manera directa en la interacción con el bebé.

El padre una figura primaria en la construcción psíquica del nino introduce la diferencia en relación a la madre, actúa contextualizando la relación madre-hijo y es agente separador y promotor del desarrollo del nino. 


\section{GRAFO Working Papers}

Número 3, enero 2014. No 03/01. ISSN: 2014-5993

En la formación de la triada primaria la madre designa al padre y éste, al aceptar la paternidad, afilia al hijo en su estirpe familiar y en su cultura. De esta manera, el niño es incorporado en la cultura familiar y ocupa un espacio simbólico en la narración de la cadena generacional.

\section{Bibliografía}

Emde, R. (1990). "Mobilizing fundamental modes of development: Empathy, availability and therapeutic action". Journal. Amer. Psychoanal. Assoc., 38, 4, pp. 881-914.

Devereux, G.(1985). Ethnopsychalyse Complémentariste. París: Flammarion

Freud, S. (1923). El yo y el ello. Buenos Aires: Amorrortu vol. XIX.

(1914). Tótem y Tabú. Obras completas. Buenos Aires: Amorrortu, vol. XIII. (1905). Tres ensayos de una teoría sexual. Buenos Aires: Amorrortu, vol. VII. (1900). La interpretación de los sueños. Buenos Aires: Amorrortu, vol. IV.

Green, A. (1977). "L'atome de la parenté et relations œedipiennes" en Lévi-Strauss, C. et al. L'identité, Séminaire dirigé par Claude Lévi-Strauss. París: Grasset, pp. 81-99.

Kaes, R. et al. (1993). Transmission de la vie psychique entre générations. París: Dunod.

Solís Pontón, L. (dir.) (2002). La parentalité, défi pour le troisième millénaire. París: PUF, le fil rouge. [Traducido al español en 2004: La parentalidad. Desafío para el tercer milenio. México D.F: El Manual Moderno].

Solís Pontón, L.; Lartigue Becerra, T; Maldonado Duran, M. (dirs.) (2006) La cultura de la Parentalidad, antidoto contra la violencia y la barbarie. México D.F.: El Manual Moderno 